\title{
An Evaluation on Engineering Identity of K-12 Youth Using the Engineering Ambassador Network (Evaluation)
}

\section{Ms. Sally T. Wei, University of Nebraska, Lincoln}

Sally Wei is the Director of K-12 Engineering Education and Outreach for the College of Engineering at the University of Nebraska-Lincoln. She also serves at the advisor for the Nebraska chapter of the Engineering Ambassadors Network. Prior to this role, Sally has worked over twenty years as an engineer in the computer industry. She holds a B.S. in Computer Science from the University of Illinois, a M.S. in Electrical Engineering from the University of Colorado, and a Master of Arts in Teaching from Union Graduate College (now Clarkson University) in New York.

\section{Dr. Trish Wonch Hill, University of Nebraska, Lincoln}

Dr. Trish Wonch Hill is an applied sociologist who collaborates with scientists across STEM disciplines to investigate how to spark STEM career interests during childhood and adolescence. She is particularly interested in how to find STEM pathways for youth who belong to historically underrepresented groups (girls, rural youth, race/ethnic minorities). 


\title{
An Evaluation on Engineering Identity of K-12 Youth Using the Engineering Ambassadors Network (Evaluation)
}

\begin{abstract}
:
The vast majority of people have only a minimal understanding of engineering and technology and its ubiquitous presence in their lives. The importance of instilling these principles at a young age is the focus of many engineering outreach programs today. But how do we quantify and measure the outcomes of such efforts? This paper focuses on one such program, the Nebraska chapter of the Engineering Ambassador Network (EAN) and an evaluation study developed to gather preliminary quantifiable data for this initiative.
\end{abstract}

EAN is a national professional development program with an outreach mission. The University of Nebraska chapter of EAN (N-EAN) consists of a team of talented, highly motivated, and passionate engineering undergraduate leaders, who seek to inspire K-12 youth via engaging presentations and hands-on activities on various relevant engineering topics.

Since the program inception in 2015, N-EAN has reached over 15,000 K-12 students statewide via school and on-campus visits. However, there has been little quantitative measure of the effectiveness of the program other than number of youth reached. The question remains on whether these visits really have an impact on K-12 youth and their attitudes towards engineering. The purpose of this pilot study was to develop statistical diagnostics to gain preliminary insight into this question.

In the Spring of 2017 a study assessed the impact of an N-EAN visit on youth from four schools in lower elementary (first grade), upper elementary (fourth grade), middle school (seventh grade) and High School (tenth grade). An instrument was developed that assessed attitudes toward engineering and engineering identity. The younger age groups were asked to draw an engineer. The survey was administered by the teacher prior to the N-EAN presentation, and the postsurvey data was collected shortly thereafter. Paired t-tests of the results have shown that there was a significant change from pre- to post-test on youth knowledge about engineering, and how much they thought engineering helped people. For high school and middle school aged youth, there was a significant increase from pre- to post-test on student interest, enjoyment, knowledge, engineering career aspirations, and a reduction in male gender bias toward engineers. This paper will discuss methodology and results of the study, impact on K-12 engineering identity, and future work in quantifying N-EAN initiatives.

\section{Introduction:}

The universal presence of engineering and technology is inescapable in today's modern world. Our lives are increasingly defined by and dependent upon technology. Essential skills needed for Americans in the $21^{\text {st }}$ century will include increased understanding of these technologies and the ability to make informed decisions about its development and use[1]. One of the most effective ways to ensure greater awareness is to provide exposure to more engineering in $\mathrm{K}-12$ education. The key to educating students to thrive in this competitive global economy is introducing them early to engineering design skills and concepts[2]. It not only helps them to 
make connections between the classroom and the real world, but instructs them in vital skills such as problem solving, critical thinking, communication, and team building[3], [4]. These engineering "habits of mind" become part of a student's mental toolkit, teaching them skills necessary to solve problems and derive meaning from their world[5]. These tools are beneficial to them regardless of chosen professions, and teaches them to function intelligently and thoughtfully in a modern technological society[4].

In addition to becoming technologically literate and educated in the engineering habits of mind, youth must also see engineering as a viable career option. There is a growing body of research suggesting Americans are falling behind other nations in K-12 STEM education[6]-[9]. There are also significant gaps in achievement between student population groups. Participation of women and underrepresented minorities must be broadened in STEM fields[7], [8], [10]-[13]. Because of this, the U.S. faces a critical shortage of students pursuing STEM majors and careers, particularly in engineering. A steady "pipeline" of diverse students prepared to pursue careers in various engineering and technical fields is needed[14]. These workforce shortages deem it essential to provide awareness and identification of these career options at a young age[11,A].

There are numerous ways to provide engineering education in the K-12 community. Formal engineering curricula is only beginning to creep into classrooms[16]. Industry and university outreach programs are also being used to fill in the gap[4]. The Engineering Ambassadors Network (EAN), formed by Pennsylvania State University in 2009, is one such outreach program[17]. The Engineering Ambassadors Network is now a collaboration of thirty universities nationwide, dedicated to K-12 engineering outreach[17],[18]. The University of Nebraska chapter of the Engineering Ambassadors Network (N-EAN) was established in 2015 in order to provide a mechanism for K-12 engineering outreach across the state. Competitively selected undergraduate engineering students are trained extensively in communication and leadership skills to deliver to K-12 classrooms, engaging presentations on relevant engineering topics paired with age appropriate hands-on activities.

Three elements distinguish the Engineering Ambassador Network outreach programs from other such programs. First, the network's messages are based upon the National Academy of Engineering's Changing the Conversation, a document on improving public understanding of engineering and ways to message it[19]. Second, the engineering ambassadors (EAs) themselves are highly motivated and energetic, engineering students who are passionate about outreach. They are chosen via a highly selective process and put through extensive communications training. And finally, the messages are delivered using advanced presentation techniques taught to the EAs during their training. Presentations are TED-style talks that are engaging for young audiences[17],[20].

There is no doubt that university outreach programs can be beneficial in promoting engineering to K-12 audiences. However, they can also be a resource drain. Are there ways to quantify the effectiveness of a program? Regarding the EAN, studies have been done on the benefits of the program to the EAs themselves[17]. However, very little quantifiable data has been collected on the program's effect on K-12 audiences other than number of youth reached. Given the fact that most EAN visits generally consist of only one or two visits per school per year, measuring impact can be challenging. This paper will discuss a pilot evaluation study of the Nebraska 
Engineering Ambassadors Network, impact on youth at four local schools at specific grade levels, preliminary results, and future directions.

\section{Evaluation Questions}

Each year dozens of teachers in a multitude of school districts across the state request visits from the Nebraska Engineering Ambassador Network (N-EAN) to provide engaging presentations and hands-on interactive activities to demonstrate basic science and engineering principles. Since 2015 they have reached over 15,000 youth, but impact has not been directly measured. The purpose of this study was to develop statistical diagnostics to gain preliminary insight into the following questions as a result of a N-EAN visit:

1. What are current perceptions of engineers and engineering by K-12 youth?

2. Can a single N-EAN visit make a difference in the engineering attitudes and perceptions of K-12 youth? Could there be an impact on subgroups of youth, but not others?

3. What are the nature of implicit and explicit gender biases in engineering for younger and older youth, and can a single N-EAN visit reduce bias?

\section{Participants and Study}

In this pilot study, four engineering ambassadors (EAs) from N-EAN were chosen, two male/female teams, to present the same presentation and hands-on activity to four area schools. The schools were selected according to diversity and grade level. The levels included, lower elementary (first grade, four classes), upper elementary (fourth grade, two classes), middle school (seventh grade, two science classes) and high school (grades 10-12 in two science classes). In total, there were 222 participants: 127 elementary (lower and upper), and 95 middle school and High School age youth.

The evaluation consisted of six surveys overall; a pre-survey and post-survey for each of the three levels of youth in the study. The three levels were defined as lower elementary youth, upper elementary youth, and middle/high school youth. Questionnaires asked questions related to youth knowledge and feelings about engineers and engineering, as well as some demographic information. All surveys can be found in Appendix A.

Prior to each N-EAN visit, pre- and post-surveys were sent to each school along with instructions for administration, parental notification forms, and youth assent forms. Youth were given the pre-survey before they participated in the N-EAN visit. After the visit, the post-survey was distributed. Post-surveys were generally administered either immediately after the event or the next day. Surveys were designed to be taken in five to ten minutes and were administered on paper.

The format for each school visit was similar. EAs from N-EAN, one male and one female began each visit with the same Roller Coaster presentation. The presentation was an interactive, engaging, "TED-style" talk about the design, physics, and engineering of roller coasters. The presentation was followed by a hands-on activity in which youth worked in groups to design their own roller coasters using foam pipe insulation, masking tape, and marbles. Youth were 
challenged to use the engineering design process and work in teams to design marble roller coasters with hills and loops. Upon completion of the activity, the EAs provided a wrap-up of the event. Teachers were encouraged to wait a day or two to administer the post-surveys, but most distributed them immediately.

\section{Measures}

For this study, we assessed differences in engineering attitudes, pre- and post- N-EAN visits for elementary (includes both lower and upper) and middle school/high school samples.

Additionally, we assessed changes in attitudes for elementary and middle school/high school age youth as a whole and explored differences by gender. For non-open ended questions (including "draw an engineer"), we used the quantitative items and paired t-tests, and assessed changes in attitudes towards engineering from pre- to post- for all youth who completed the quantitative items at both time points. Altogether, the analytic sample using these questions, includes 80 elementary age youth and 62 middle school/high school age youth. A few youth completed only the pre-test survey, while others completed only the post-test. Results are reported for the two age groups (elementary and middle/high school) separately.

Assessing attitudes of lower elementary youth, particularly first graders, can be challenging. Given this difficulty, we decided to use the "Draw an Engineer Test" (DAET)[21] and asked youth to draw their perception of what an engineer is on both pre- and post-surveys. Upper elementary youth could draw or use words to describe an engineer and also answered the question, "What do engineers do?" All elementary age youth were also asked on pre- and postsurveys, "How much do you like engineering?" and "How much does engineering help people?" Response categories were "A lot" "Some" "A little" or "Not at All". Lastly, youth were asked to complete the statement, "Engineering is mostly for ... " with the response categories as "Boys," "Girls," or "Both Boys and Girls."

Middle school and high school youth were also asked an open-ended question, "What do engineers do?" Additionally, they were given several statements about engineers and asked how much they agreed or disagreed with them. Middle school and high school age youth were asked to rate, using a five point Likert scale (strongly agree, agree, neither agree/nor disagree, disagree, strongly disagree), their perceptions of the following:

1. Engineering impacts my daily life

2. Engineering is about problem solving

3. Engineers work mostly by themselves

4. Engineering is mostly for boys/men

5. Engineers help people

6. Engineers are creative

7. Engineers fix and repair things

8. Engineers develop new kinds of toothpaste

9. Engineers design water bottles 
Middle and high school age youth were also asked, "How much would you like to become an engineer?" Response categories for this question were, "A lot," "Some," "A little," and "Not at all."

In addition to asking about their attitudes toward engineering, youth were also asked their gender and, for middle school/high school age youth, their race/ethnicity. Elementary level age youth were not asked their race/ethnicity, but based on the schools selected, they represent a broad range of racial/ethnic diversity. The school selected for the lower elementary level is comprised of $>65 \%$ of youth who identify as a race/ethnic minority, and for the upper elementary, $>44 \%$ identify as a racial/ethnic minority. Of the 80 youth with complete data, $53.6 \%$ were girls.

Among the middle school and high school age youth in our sample, $14.5 \%$ identified as Hispanic or Latino/a, 12.9\% as African or African American, 6.5\% as American Indian, $4.8 \%$ as Asian, and $22 \%$ as other, $71 \%$ as white/Caucasian. Youth could choose more than one race/ethnicity category. Altogether, $>45 \%$ of youth who completed the surveys were a racial/ethnic minority. Additionally, of the 62 youth, $50 \%$ were girls.

\section{Methods}

All elementary youth were asked to "draw an engineer" while upper elementary, middle and high school youth were asked, "What does an engineer do?". Responses to these questions, drawn and written, were reviewed with recurring themes translated into codes. For elementary age youth two independent coders identified twelve categories for "Draw an engineer" and ten category codes for "what does an engineer do?" For middle/high school age youth, nine categories were identified for "what does an engineer do?" Each drawing was coded by marking if a category was present in the drawing. For the written responses, words corresponding to each of the code categories were recorded. "Draw an engineer" drawings were coded for both pre- and postsurveys, according to the following categories: tool related, cars/vehicle related, computers/office related, building related, train related, hat on figures, roller coaster related, person (female), person (male), stick/generic person, don't know, or other. For the question, "What does an engineer do?" descriptions were coded with responses similar to the following categories: build/construct, design/model, drive (trains), cars/machines related, help people, roller coaster related, solve problems, don't know, other.

For quantitative items, we used SPSS version 22 to analyze data for elementary and middle school/high school age youth separately. Prior to calculating descriptive statistics, we recoded variables so that a high value for the variable indicates agreement or a positive response. Then we calculated descriptive statistics for both the elementary sample and the middle school/high school age sample. We used independent sample t-tests to assess any pre- and post- differences for boys and girls in each sample. Finally, we used paired t-tests to assess change in engineering attitudes for both groups as a whole, and by gender. 


\section{Results}

\section{Elementary}

Before assessing how much youth agreed or disagreed with statements about their attitudes regarding engineers and engineering, it was important to assess if they knew much about engineering in general. Particularly for youth in elementary schools, who may not have much exposure to engineering ideas, they may not know what an engineer is or does. Findings for the "Draw an engineer" and "What does an engineer do?" questions for elementary age youth are shown in Figures 1 \& 2 .

Figure 1. Pre- and post- survey results (elementary) for "Draw an engineer" question.

\section{DRAW AN ENGINEER (ELEMENTARY)}

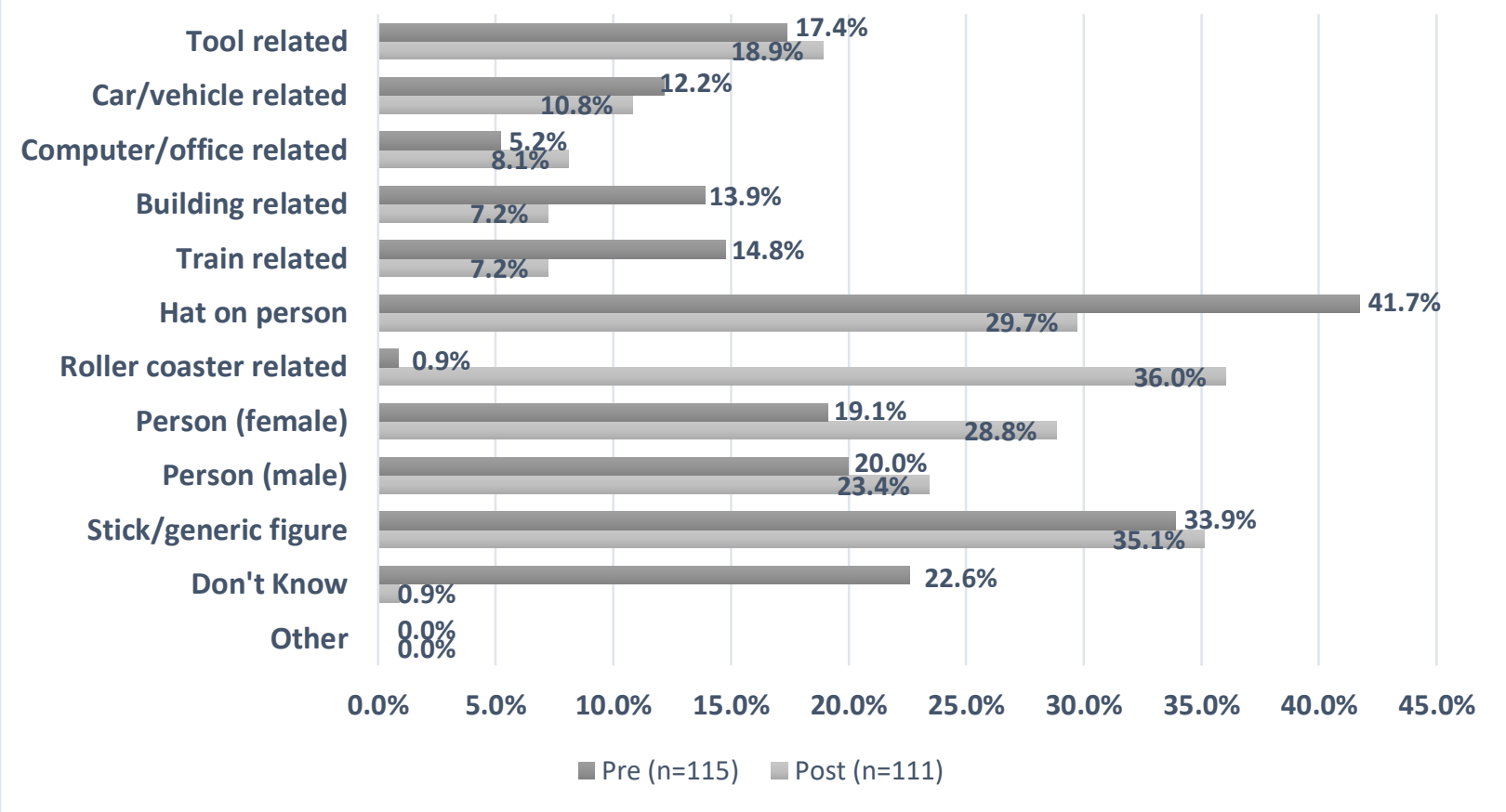


Figure 2. Pre- and post- survey results (upper elementary) for "What do engineers do?" question.

\section{WHAT DO ENGINEERS DO? (UPPER ELEMENTARY)}

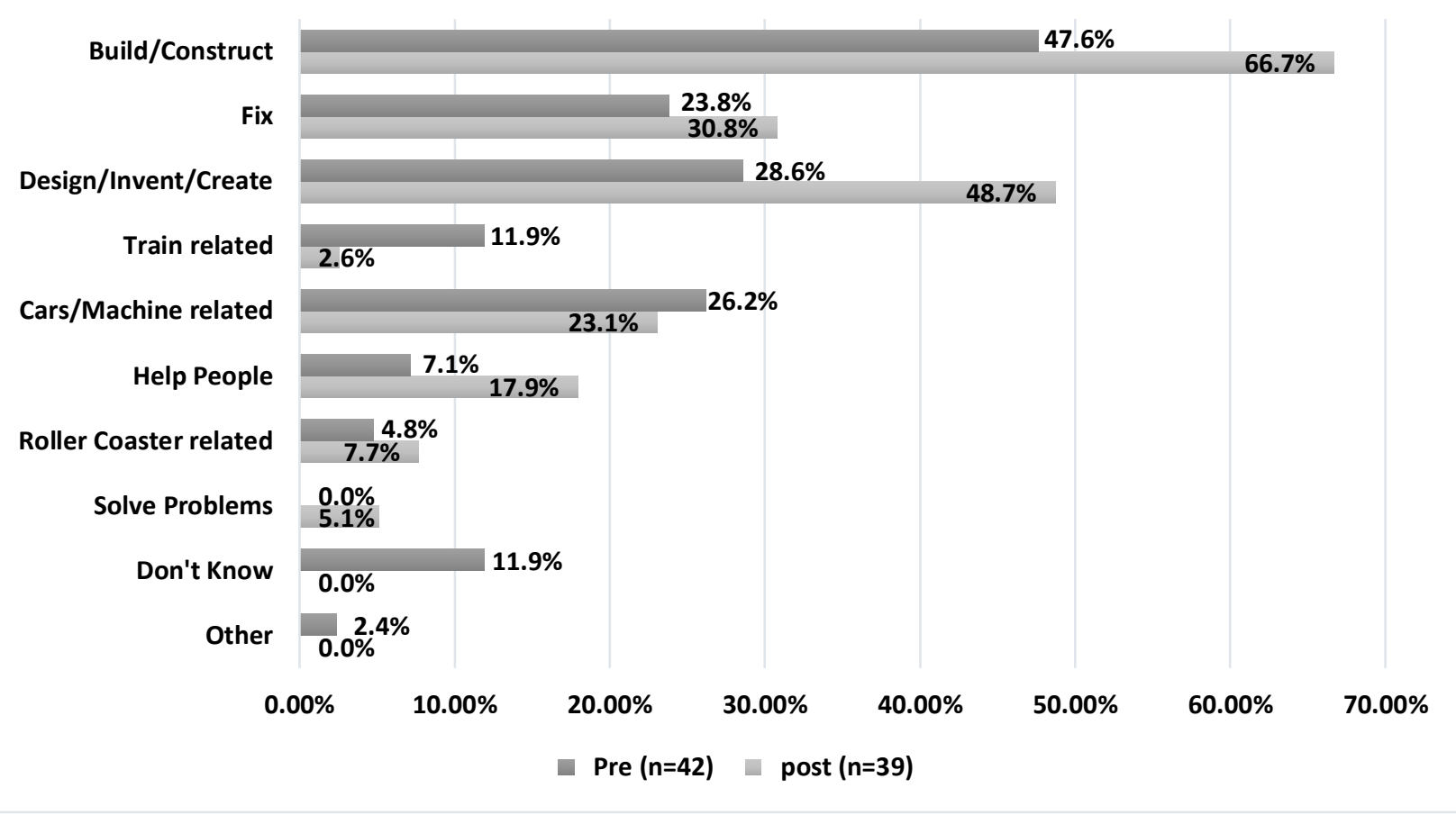

The elementary group showed notable changes from pre- to post- for "Draw an engineer" in a few categories. Prior to the N-EAN visit, 22.6\% indicated they did not know what an engineer was, which dropped to $0.9 \%$ following the visit. Train related drawings comprised $14.8 \%$ of elementary pre-surveys, compared to $7.2 \%$ in post-survey drawings. Relating engineering to roller coasters increased greatly (particularly among lower elementary youth), but can be attributed to the fact that the topic of the presentation was about roller coasters. A "hat" category was also included because so many of the drawings included figures wearing hats. Some seemed to be train related while others were construction related. It is interesting to note that elementary youth equated engineers with wearing hats, though we cannot comment on the significance of this observation.

The upper elementary, middle, and high school age youth were asked to answer the open-ended question, "What does an engineer do?" Upper elementary results are shown in Figure 2. For this group, it can be observed that the use of words, design/invent/create increased from $28.6 \%$ to $48.7 \%$ from pre- to post- surveys. Train related descriptions decreased from $11.9 \%$ to $2.6 \%$ and the perception that engineers help people increased. Similar to the drawings, the number of upper elementary youth who stated they didn't know what an engineer did, decreased to $0.0 \%$.

Overall, elementary age youth reported positive attitudes towards engineering before and after the N-EAN visit. 39\% reported they like engineering "A lot" and another 20\% reported they like engineering "Some". This increased substantially pre- to post- N-EAN visit. After the N-EAN visit, $68 \%$ of elementary age youth reported they like engineering, "A lot" and $23.8 \%$ said they 
liked it "Some". Paired t-tests show that this increase from pre- N-EAN visit to post- N-EAN visit was statistically significant (pre- mean $=1.8$ post- mean $=2.6, \mathrm{p}<.001$ ). We did not find any meaningful or statistically significant difference in pre- or post- attitudes by gender on these variables. Detailed descriptive statistics for quantitative items for both elementary and middle school/high school age youth can be found in Table 1 of Appendix B.

When asked, "How much do engineers help people?" $65 \%$ of elementary age youth responded, "A lot" and 26.3\% said "Some". After the N-EAN visit, $84 \%$ of youth said engineers helped people "A lot" and 15\% said some. Paired t-tests show that this increase from pre- N-EAN visit to post- N-EAN visit was statistically significant (pre- mean $=2.6$ post- mean=2.8, $\mathrm{p}<.05$ ). We did not find any meaningful or statistically significant difference in pre- or post- attitudes by gender on these variables.

On perceptions of whether engineering was for boys or girls, we found that all elementary age youth overwhelming think that engineering is for both boys and girls at both time points. Prior to the N-EAN visit, $85 \%$ of youth reported that engineering was for both boys and girls, and after the N-EAN visit $90 \%$ reported engineering was for both boys and girls. This change was not statistically significant and we found no statistically significant differences between boys and girls. Among the small number who reported that engineering was mostly for boys or mostly for girls, we found that a handful of both boys and girls, almost all reported engineering was mostly for boys.

Although we did not find an explicit gender bias for elementary age youth in our study, some possible implicit biases were apparent in the "draw an engineer" drawings. At the pre-test, $19.1 \%$ of youth drew an engineer that was female. No boys drew a female engineer at the pretest, and 29\% of total girls did. Approximately $23 \%$ of boys drew a male engineer, as well as $17 \%$ of the girls, and the difference was not statistically significant $(\mathrm{p}<.05)$. At post-test, boys were no more likely to draw a female or a male engineer than at the pre-test, and the proportion of girls who drew a male engineer did not change either, although there was an increase in the proportion of girls who drew a female engineer, $40 \%$ of girls did so at post-test.

\section{Middle School/High School}

Middle school and high school age youth were asked the open-ended question, "What do engineers do?" Results are displayed in Figure 3. Although they seemed to have a better understanding then younger youth, there was only a slight decrease in the proportion who wrote, "I don't know". This was a surprising result. We found that the "I don't know" response was only recorded by middle school age youth (no high school) and attribute the higher rate of this response in part, to the fact that blank responses were also coded as "I don't know" rather than disregarded. 
Figure 3. Pre-and post- survey results (middle school and high school) for "What do engineers do?" question.

WHAT DO ENGINEERS DO? (MIDDLE/HIGH SCHOOL)

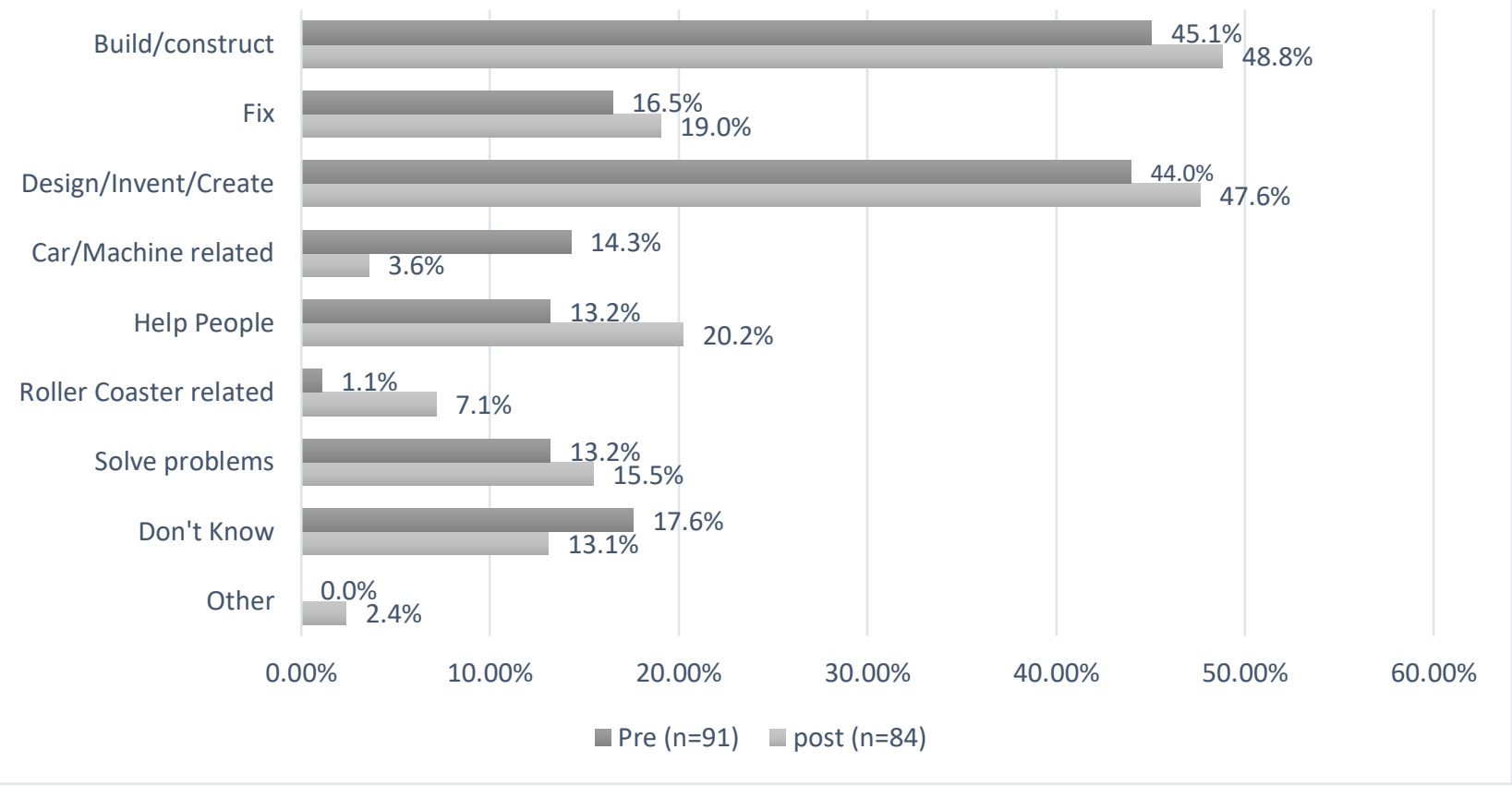

Among middle and high school age youth we found significant increases from pre- to post- $\mathrm{N}$ EAN visit on five of the eight indicators. There was a significant increase in positive perceptions on the relevance and utility of engineering; whether engineering impacts their daily life, or if it is about problem solving. In addition, compared to before the N-EAN visit, middle and high school age youth were more likely to say engineers are creative, and that they fix and repair things. Other questions, such as "engineers develop new kinds of toothpaste" and "engineers design water bottles" were included in order to gauge the breadth of student understanding of how engineering impacts their everyday lives; that engineering is literally all around them. Though not specific to their presentation, the EAs addressed this to some degree, which was reflected in the post- surveys, but not significantly. Results of the paired t-tests for middle and high school age youth can be found in Table 2 of Appendix B.

Unlike elementary age youth, for middle and high school age youth, there were interesting and significant gender differences among middle school and high school age youth on some measures. First, looking at differences in the pre-test prior to N-EAN visit, we found gender differences on two variables. We found that prior to the visit, boys, on average had higher agreement with the perception that engineering is about problem solving compared to girls, and that this difference was statistically significantly different ( $\operatorname{girls}=3.6 \mathrm{vs}$. boys $=4.0, \mathrm{p}<.05)$. Also, prior to N-EAN visits, boys were more likely to say they want to become an engineer ( girls $=.8$ vs. boys $=1.4, \mathrm{p}<05$ ), although on a 4-point scale, these means are generally low for both groups. Otherwise, we did not see significant gender differences at the pre-test. At post-test, there were some mean differences between boys and girls, however, none were statistically significant. 
However, given the small sample size, we may simply not have the statistical power to generalize.

Figure 4. Engineering attitudes pre- and post- $N$-EAN visit by gender.

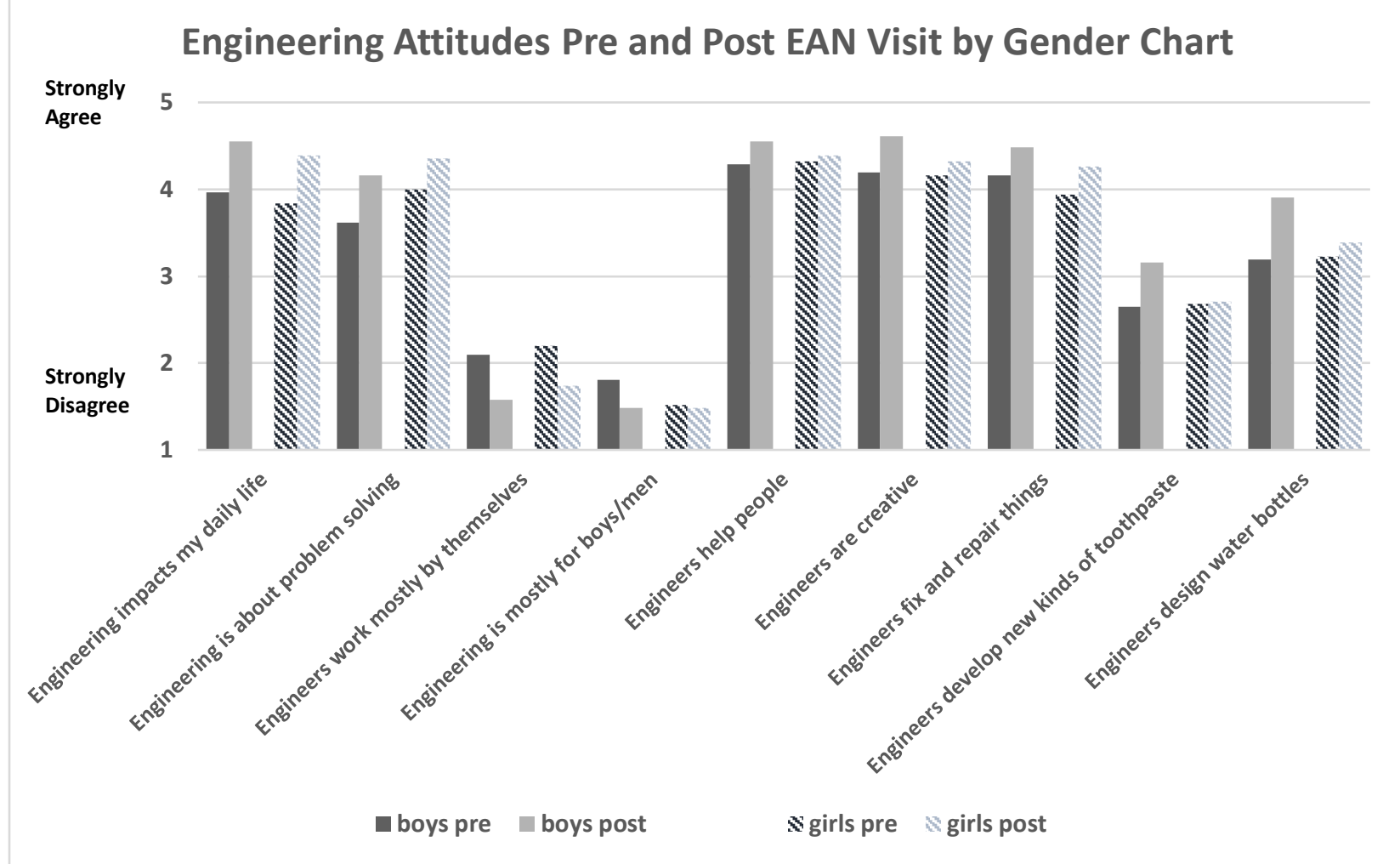

Using paired t-tests by group, we also assessed whether boys or girls had significantly different changes in attitudes from pre- to post-. We found that for boys only, there was a statistically significant reduction, on average, in agreement that engineering is mostly for boys. For girls, there was a statistically significant increase in agreement with the statement that engineering helps people.

\section{Discussion}

The results of this pilot study indicate that the youth in this study responded favorably overall to an N-EAN visit. Elementary youth reported more knowledge and interest in engineering after the N-EAN visit than before. There was also an increase in perception on how much engineers help people. There was little to no change in attitudes by gender by elementary youth, at least when asked explicitly. However, girls were more likely to draw a female engineer after the $\mathrm{N}$ EAN visit, perhaps due to the fact that one of the EAs was female.

For middle to high school age youth, positive perceptions of engineering also showed a marked increase following the N-EAN visit. This age group yielded more gender differences in that more boys related engineering to problem solving than girls. Also a greater number of boys saw themselves as future engineers in the pre- survey, than girls. Although this number increased slightly post- visit for both genders, it is not statistically significant. 
Youth seemed generally responsive to the N-EAN visit due to several factors: The EAs are closer to youth's ages, act as engineering role models (particularly for females), deliver engaging and interactive presentations, and challenge and question youth during the hands-on activities. Moreover, during and after the presentation, youth are told that engineers help people, engineering is creative and fun, and that engineers improve the health, happiness, and safety of the world. The engineering design process is also introduced in all presentations and emphasized throughout the hands-on activity. Youth are told that they will be "roller coaster engineers" prior to the hands-on activities and must work in teams.

Generally speaking, we can state that a single N-EAN visit does have an immediate and positive impact on youth of all ages, from lower elementary to high school. Whether they retain these attitudes is yet unclear. In this study, post-surveys were administered either immediately or a day following the N-EAN visit. Ideally, we would administer the post-survey a week later, followed by several months later in order to measure retention impact of a single visit. Gender differences by age and assessing implicit and explicit attitudes were not possible with these small samples sizes. Additional evaluation with larger sample sizes would be needed to further explore the associations we found. Ideally, male and female EAs would be randomly assigned to test if the ambassador gender or ethnicity makes a difference.

\section{Future Directions}

The N-EAN appears to be an excellent means of engineering outreach throughout the state for the K-12 community, producing increased enthusiasm and understanding of engineering. More work must be done to quantify these efforts. In future studies, we plan to measure the impact of multiple visits to the same classroom over a single academic year. As mentioned previously, we would ask teachers to administer post- surveys at least a week or longer after the N-EAN visit to measure retention of information. More work must also be done in finding better ways to directly correlate survey questions with EA interactions with youth. We would also like to initiate some longitudinal studies with the same class of youth over a period of time. Although we collected some data on race/ethnicity, we did not have a large enough sample size to draw any definitive conclusions. In addition to gender attitudes towards engineering, we would like to focus on race/ethnicity as well and study the impact of EA role models on youth.

\section{Conclusions}

This paper has outlined an initial pilot study designed to gather seed data for future studies on the impact of a single N-EAN visit on K-12 youth and engineering identity. The ultimate goal of the evaluation is to build a statistically significant data base for analysis and assessment of K-12 outreach activities related to the N-EAN. In this study, a total of 222 participants from four K-12 age groups, lower and upper elementary, middle and high school were queried about their understanding and attitudes regarding engineering and engineers. Based on the results available to date, we can conclude that N-EAN visits:

- Create positive attitudes and enthusiasm towards engineering among K-12 youth.

- Can reduce explicit gender bias among middle and high school boys. 
- Increase girls' implicit perception that they can be engineers.

As we continue to build and study the longitudinal dataset, we will be able to assess the longrange efficacy of N-EAN K-12 interactions, as a viable and effective means of engineering outreach.

\section{Acknowledgements:}

We wish to thank the Social and Behavioral Sciences Research Consortium (SBSRC) and the Bureau of Sociological Research for their support of this project. We also would like to thank the Lincoln Public School teachers, administrators, and students as well as the Nebraska Engineering Ambassador Network for their willingness to participate in this study.

\section{References:}

[1] T. Speaking, "Why All Americans Need to Know More about Technology," in National Academy of, 2002.

[2] T. Willard, NSTA Quick-Reference Guide to the NGSS, K-12. Arlington, VA: NSTA Press, 2015.

[3] B. M. Capobianco, H. A. Diefes-Dux, I. Mena, and J. Weller, "What is an engineer? Implications of elementary school student conceptions for engineering education," J. Eng. Educ., vol. 100, no. 2, p. 304, 2011.

[4] N. R. Council, Engineering in K-12 education: Understanding the status and improving the prospects. National Academies Press, 2009.

[5] T. J. Moore, K. M. Tank, A. W. Glancy, and J. A. Kersten, "NGSS and the landscape of engineering in K-12 state science standards," J. Res. Sci. Teach., vol. 52, no. 3, pp. 296318, 2015.

[6] D. Kelly, C. W. Nord, F. Jenkins, J. Y. Chan, and D. Kastberg, "Performance of US 15Year-Old Students in Mathematics, Science, and Reading Literacy in an International Context. First Look at PISA 2012. NCES 2014-024.," Natl. Cent. Educ. Stat., 2013.

[7] C. Hill, C. Corbett, and A. St Rose, Why So Few? Women in Science, Technology, Engineering, and Mathematics. ERIC, 2010.

[8] “nsf.gov - Digest 2015: Women, Minorities, and Persons with Disabilities - NCSES - US National Science Foundation (NSF)." [Online]. Available: http://www.nsf.gov/statistics/2015/nsf15311/digest/theme3.cfm. [Accessed: 24-Jun-2016].

[9] J. P. Holdren, E. S. Lander, and H. Varmus, "Prepare and inspire: K-12 education in science, technology, engineering, and math (STEM) for America's future," Exec. Rep. Wash. DC Pres. Counc. Advis. Sci. Technol., 2010.

[10] J. A. Bianchini, "Expanding underrepresented minority participation: America's science and technology talent at the crossroads," Sci. Educ., vol. 97, no. 1, pp. 163-166, 2013.

[11] P. W. Hill, J. McQuillan, A. N. Spiegel, and J. Diamond, "Discovery Orientation, Cognitive Schemas, and Disparities in Science Identity in Early Adolescence," Sociol. Perspect., p. 073112141772477 , Aug. 2017.

[12] S. N. Alegria and E. H. Branch, "Causes and Consequences of Inequality in the STEM: Diversity and its Discontents," Int. J. Gend. Sci. Technol., vol. 7, no. 3, pp. 321-342, 2015. 
[13] National Science Board, Science and Engineering Indicators 2016. Arlington, VA: National Science Foundation.

[14] C. R. Østergaard, B. Timmermans, and K. Kristinsson, "Does a different view create something new? The effect of employee diversity on innovation," Res. Policy, vol. 40, no. 3, pp. 500-509, Apr. 2011.

[15] S. H. Degenhart, G. J. Wingenbach, K. E. Dooley, J. R. Lindner, D. L. Mowen, and L. Johnson, "Middle school students' attitudes toward pursuing careers in science, technology, engineering, and math," NACTA J., 2007.

[16] J. P. Van Overschelde, "Project Lead The Way students more prepared for higher education," Am. J. Eng. Educ., vol. 4, no. 1, p. 1, 2013.

[17] C. Talbot, M. Alley, M. Marshall, C. Haas, S. E. Zappe, and J. K. Garner, "Engineering Ambassador Network: Professional development of the engineering ambassadors," in 120th ASEE Annual Conf, 2013.

[18] Engineering Ambassadors Network. (2018). Engineering Ambassadors Network Home Page. [online] Available at: http://www.bing.com/cr?IG=C6186A2F2D9B4332B88EF892EFE512CD\&CID=0C31980 A58D66D1F2D1D938659796C31\&rd=1\&h=LJHSvAYoCnzY6PrifdrAhw 1aDhwylC41cw Ao56067iw \&v=1\&r=http\%3a\%2f\%2fwww.engineeringambassadors.com\%2f\&p=DevEx,5 068.1 [Accessed 4 Feb. 2018].

[19] National Academy of Engineering, Ed., Changing the conversation: messages for improving public understanding of engineering. Washington, D.C: National Academies Press, 2008.

[20] A. N. Krupa, M. Marshall, M. Alley, J. K. Garger, C. Haas, and J. G. Hatzell, "Engineering Ambassador Network: Increasing Diversity through Outreach to Middle and High Schools," in 120th ASEE Annual Conf, 2013.

[21] M. Knight and C. Cunningham, "Draw an engineer test (DAET): Development of a tool to investigate students' ideas about engineers and engineering," in ASEE Annual Conference and Exposition, 2004, vol. 2004. 
Appendix A. Surveys

Figure A1. Lower elementary pre- and post- surveys.

1. Please draw a picture of an engineer
$\quad \quad$ full page)
2. How much do engineers help people?
A lot
Some
A little
Not at all
3. How much do you like engineering?
A lot
Some
A little
Not at all
4. Engineering is mostly for...
Boys
Girls
Both boys and girls
5. Are you a boy or a girl?
Boy
Girl

Engineering Ambassadors Post-Survey Lower Elementary Level

Name: School:

1. Please draw a picture of an engineer: (full page)

2. How much do engineers help people? A lot

Some

A little

Not at all

3. How much do you like engineering?

A lot

Some

A little

Not at all

4. Engineering is mostly for...

Boys

Girls

Both boys and girls

5. I liked the Engineering Ambassador visit. A lot

Some

A little

Not at all

6. Are you a boy or a girl?

Boy

Girl 
Figure A2. Upper elementary pre- and post-surveys.

Engineering Ambassadors Pre-Survey

Upper Elementary Level

Name:

1. What do Engineers do?

2. Please draw a picture of an engineer OR Describe what an engineer looks like :

3. How much do engineers help people?

A lot

Some

A little

Not at all

4. How much do you like engineering?

A lot

Some

A little

Not at all

5. Engineering is mostly for... Boys

Girls

Both boys and girls

6. Are you a boy or a girl?

Boy

Girl
Engineering Ambassadors Post-Survey

Upper Elementary Level

Name:

1. What do Engineers do?

2. Please draw a picture of an engineer OR Describe what an engineer looks like :

3. How much do engineers help people?

A lot

Some

A little

Not at all

4. How much do you like engineering?

A lot

Some

A little

Not at all

5. Engineering is mostly for...

Boys

Girls

Both boys and girls

6. I liked the Engineering Ambassador visit A lot

Some

A little

Not at all

7. Are you a boy or a girl?

Boy
Girl 
Figure A3. Middle/High pre- and post-surveys.

\section{Grade6-12 Student Pre-Survey}

平

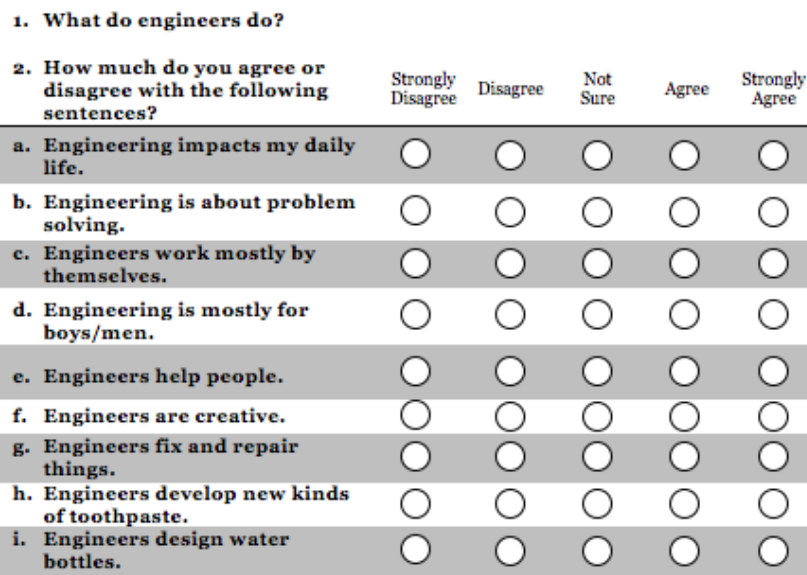

3. How much would you like to become an engineer someday?
A lot
Some
A little
Not at all

4. Are you:

Male

Oemale

5. Do you consider yourself to be Hispanic or Latino/a?

$$
\text { Ynes }
$$

6. Which one or more of the following would you say is your race? Select al apply.

$\square$ white

$\square$ Black or African American

$\square$ American Indian or Alaska Native

$\square_{\text {Asian }}$

$\square$ other

\section{Grade6-12 Student Post-Survey}

本

1. What do engineers do?

2. How much do you agree

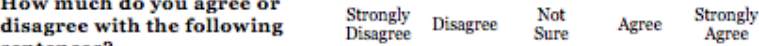

a. Engineering impacts my daily $\bigcirc \quad \bigcirc \quad \bigcirc \quad \bigcirc \quad \bigcirc$

b. Engineering is about problem $\bigcirc \quad \bigcirc \quad \bigcirc \quad \bigcirc \quad \bigcirc$

Engineers w.
themselves.

○ $\bigcirc \bigcirc \bigcirc \bigcirc$

d. Engineering is mostly for boys/men.

e. Engineers help people.

f. Engineers are creative. ○ 0000

Engineers fix and repair $\begin{array}{lllll}0 & 0 & 0 & 0 & 0\end{array}$

things. O 0000

h. Engineers develop new kinds of toothpaste.

i. Engineers design water bottles.

3. How much would you like to become an engineer someday? A lot

Some

A little

Not at all

4. Has the Engineering Ambassador visit changed the way you think about engineering, and if so, how?

5. Are you:
Male
Female
Other

6. Do you consider yourself to be Hispanic or Latino/a? Yyes No

7. Which one or more of the following would you say is your race? Select all that apply.

$\square$ white

$\square$ Black or African American

$\square$ American Indian or Alaska Native

$\square$ Asian 
Appendix B: Statistics

Table 1. Descriptive Statistics

\begin{tabular}{|c|c|c|c|c|c|c|}
\hline & \multicolumn{2}{|l|}{$\underline{\text { PRE }}$} & \multicolumn{2}{|c|}{$\underline{\mathrm{POST}}$} & \multirow[b]{2}{*}{ Min } & \multirow[b]{2}{*}{ Max } \\
\hline & $\begin{array}{c}\text { Mean/ } \\
\text { Proportion }\end{array}$ & SD & $\begin{array}{c}\text { Mean/ } \\
\text { Proportion }\end{array}$ & SD & & \\
\hline \multicolumn{7}{|l|}{ Elementary $\mathrm{N}=80$} \\
\hline How much do you like engineering? & 1.9 & 0.73 & 2.6 & 0.41 & 1 & 4 \\
\hline How much do engineers help people? & 2.5 & 1.06 & 2.8 & 0.73 & 1 & 4 \\
\hline $\begin{array}{l}\text { Engineering is mostly for .. . Both Boys and } \\
\text { Girls }\end{array}$ & 0.85 & & 0.90 & & & \\
\hline \multicolumn{7}{|l|}{$\mathrm{MS} / \mathrm{HSN} \mathrm{N}=62$} \\
\hline Engineering impacts my daily life & 3.9 & 0.95 & 4.5 & 0.84 & 1 & 5 \\
\hline Engineering is about problem solving & 3.8 & 0.77 & 4.3 & 0.90 & 1 & 5 \\
\hline Engineers work mostly by themselves & 2.2 & 0.88 & 1.7 & 0.92 & 1 & 5 \\
\hline Engineering is mostly for boys/men & 1.7 & 0.94 & 1.5 & 0.90 & 1 & 5 \\
\hline Engineers help people & 4.3 & 0.69 & 4.5 & 0.65 & 1 & 5 \\
\hline Engineers are creative & 4.2 & 0.78 & 4.5 & 0.76 & 1 & 5 \\
\hline Engineers fix and repair things & 4.1 & 0.82 & 4.4 & 0.83 & 1 & 5 \\
\hline Engineers develop new kinds of toothpaste & 2.7 & 1.07 & 2.9 & 1.35 & 1 & 5 \\
\hline Engineers design water bottles & 3.2 & 0.96 & 3.7 & 1.16 & 1 & 5 \\
\hline $\begin{array}{l}\text { How much would you like to become an } \\
\text { engineer? }\end{array}$ & 1.1 & 1.02 & 1.3 & 1.03 & 1 & 5 \\
\hline
\end{tabular}

Table 2. Results of Paired t-test for Middle and High School Age Youth, Full Sample, and by Gender.

\begin{tabular}{|c|c|c|c|c|c|c|c|c|c|c|c|c|c|c|c|}
\hline & \multicolumn{5}{|c|}{ Total $\mathrm{N}=61$} & \multicolumn{5}{|c|}{ Boys $\mathrm{N}=31$} & \multicolumn{5}{|c|}{ Girls $N=31$} \\
\hline & \multicolumn{2}{|c|}{$\underline{\text { PRE }}$} & \multicolumn{2}{|c|}{$\underline{\mathrm{POST}}$} & \multirow[b]{2}{*}{ sig. } & \multicolumn{2}{|c|}{$\underline{\text { PRE }}$} & \multicolumn{2}{|c|}{$\underline{\text { POST }}$} & \multirow[b]{2}{*}{ sig. } & \multicolumn{2}{|c|}{$\underline{\text { PRE }}$} & \multicolumn{2}{|c|}{$\underline{\mathrm{POST}}$} & \multirow[b]{2}{*}{ sig } \\
\hline & Mean & SD & Mean & SD & & Mean & SD & Mean & SD & & Mean & SD & Mean & SD & \\
\hline Engineering impacts my daily life & 4.0 & 0.95 & 4.5 & 0.84 & $* * *$ & 4.0 & 0.71 & 4.5 & 0.85 & $*$ & 3.8 & 1.16 & 4.4 & 0.84 & $* * *$ \\
\hline $\begin{array}{l}\text { Engineering is about problem } \\
\text { solving }\end{array}$ & 3.6 & 0.77 & 4.2 & 0.90 & $* * *$ & 3.6 & 0.80 & 4.2 & 0.93 & $* * *$ & 4.0 & 0.68 & 4.4 & 0.88 & * \\
\hline $\begin{array}{l}\text { Engineers work mostly by } \\
\text { themselves }\end{array}$ & 2.1 & 0.88 & 1.6 & 0.92 & $* * *$ & 2.1 & 0.83 & 1.6 & 0.81 & $* * *$ & 2.2 & 0.95 & 1.7 & 1.03 & $* * *$ \\
\hline $\begin{array}{l}\text { Engineering is mostly for } \\
\text { boys/men }\end{array}$ & 1.8 & 0.94 & 1.5 & 0.90 & & 1.8 & 0.95 & 1.5 & 0.72 & $* * *$ & 1.5 & 0.93 & 1.5 & 1.06 & \\
\hline Engineers help people & 4.3 & 0.69 & 4.5 & 0.65 & & 4.3 & 0.64 & 4.5 & 0.62 & & 4.3 & 0.75 & 4.4 & 0.67 & $*$ \\
\hline Engineers are creative & 4.2 & 0.78 & 4.6 & 0.76 & $*$ & 4.2 & 0.75 & 4.6 & 0.62 & $*$ & 4.2 & 0.82 & 4.3 & 0.87 & \\
\hline Engineers fix and repair things & 4.2 & 0.82 & 4.5 & 0.83 & $* *$ & 4.2 & 0.69 & 4.5 & 0.63 & & 3.9 & 0.93 & 4.3 & 1.00 & $* * *$ \\
\hline $\begin{array}{l}\text { Engineers develop new kinds of } \\
\text { toothpaste }\end{array}$ & 2.6 & 1.10 & 3.2 & 1.40 & & 2.6 & 1.17 & 3.2 & 1.46 & $* *$ & 2.7 & 0.98 & 2.7 & 1.22 & \\
\hline Engineers design water bottles & 3.2 & 0.97 & 3.9 & 1.20 & $* *$ & 3.2 & 1.01 & 3.9 & 1.14 & $* * *$ & 3.2 & 0.92 & 3.4 & 1.15 & $* *$ \\
\hline $\begin{array}{l}\text { How much would you like to } \\
\text { become an engineer? }\end{array}$ & 1.1 & 1.00 & 1.3 & 1.00 & $*$ & 1.1 & 1.06 & 1.3 & 1.03 & $* * *$ & 0.8 & 0.90 & 1.1 & 1.01 & $* * *$ \\
\hline$* * * p<.001, * * p<.01, *<.05$ & & & & & & & & & & & & & & & \\
\hline
\end{tabular}

